\title{
INFLUENCE OF HISTORICAL BATHYMETRIC CHANGES DUE TO URBANIZATION ON THE VULNERABILITY OF STORM SURGE IN TOKYO BAY
}

\author{
Akifumi Tatekoji ${ }^{1}$, Ryota Nakamura ${ }^{2}$ and Tomoya Shibayama ${ }^{3}$ \\ In this study, the influence of historical changes on bathymetry to the intensity and features of the storm surge in the \\ Tokyo Bay is evaluated using the meteorology-ocean-tide models. In detail, storm surge of 1917 is reproduced using \\ an artificial Taisho Typhoon of 1917 in order to quantify the influence of bathymetric changes. This paper possesses \\ two important findings. The first is that past storm surge occurred mainly because of shallow water area spanning \\ over the inner bay which can be characteristics of past bathymetry. The second is that the high vulnerable area \\ affected by storm surge has been shifted from mudflat shallow area in the inner bay to the below-sea-level inland area, \\ due to landfill and urbanization which have continued approximately 100 years after the storm. As a conclusion, the \\ bathymetry shifting due to human activity has a great influence to changing the effects of coastal disasters even in the \\ same location.
}

Keywords: Storm surge, 1917 Taisho typhoon, Historical change, Tokyo Bay, WRF, FVCOM, NAO.99b

\section{INTRODUCTION}

Tokyo bay has played an essential role as major political and economic hub in Japan. Due to the economic and residential demand required for Tokyo bay, the land-use has been significantly shifted for the last one century. For example, the region including forest, grassland, rice field and other agricultural field has been significantly changed to urban and industrial region for one hundred years. Furthermore, a large amount of ground water has been pumped up for industry use during the period of the rapid economic growth, leading a result of remarkable ground subsidence. Because of the serious ground subsidence, low-lying areas, including below-sea-level areas, are widely emerged in current region near Tokyo Bay (Fig. 1), possessing a high potential to increase a risk of coastal flooding in the coastal region.

The coastal region of Tokyo Bay has been exposed to coastal disasters, such as storm surge associated with typhoon and tropical cyclones. Selected serious storm surge events happened are summarized in Table 1. Among the events, the 1917 Taisho Typhoon (hereafter, Taisho Typhoon) and its storm surge exceeded that which expected by civil engineers and coastal deference system, leading the extensive damage for non-engineering houses and a loss of 1,300 lives mainly due to the surge of $3.08 \mathrm{~m}$ highest in the inner bay (Miyazaki, 2003). Because of the result of this event, storm surges have been highlighted as one of the most serious coastal hazards, causing a large amount of losses for economy and human in Tokyo. Then, 1917 Taisho Typhoon and its storm surge has played an important impact to civil engineers in the development of disaster prevention, such as for determining the height of sea wall (Tokyo Metropolitan Government et al., 2004). Furthermore, a vulnerability of possible future storm surge has been investigated by using the Taisho Typhoon in several previous studies (Esteban et al., 2014, Hoshino et al., 2016).

During the past 100 years, in addition to the land-use shifted in land area, both the shape and depth of the bay has been remarkably changed mainly due to the land reclamation in Tokyo Bay. In fact, there existed the historical record of land reclamation in 1590 with the aim to expand residential areas and construct waste disposal sites. Through nearly 400 years, the purpose of the land reclamation was conducted to build the coastal industrial zone. Due to the long-term land reclamation, the significant change of the bay shape and ocean depth in Tokyo Bay can be considered as the one of the most remarkable cases among the world.

There was almost no storm surge caused by the fierce typhoons like 1917 Taisho Typhoon for the last several decades. This may be one of the reason for almost no discussion of the relationship between the bathymetry change and intensity of the storm surge in Tokyo Bay. Generally, it is well-known that storm surge heights are highly dependent on bathymetry and bay shape (e.g. Wadachi et al., 1939). In

\footnotetext{
${ }^{1}$ Department of Civil and Environmental Engineering, Waseda University, 3-4-1 Okubo, Shinjuku-ku, Tokyo 1698555, Japan. Email: akifumi-tatekoji@ruri.waseda.jp

${ }^{2}$ Department of Civil and Environmental Engineering, Waseda University, 3-4-1 Okubo, Shinjuku-ku, Tokyo 1698555, Japan. Email: r.nakamura6@kurenai.waseda.jp

${ }^{3}$ Department of Civil and Environmental Engineering, Waseda University, 3-4-1 Okubo, Shinjuku-ku, Tokyo 1698555, Japan. Email: shibayama@waseda.jp
} 
fact, there are almost no researches considering past bathymetry to investigate the old storm surge event in Tokyo Bay. Thus, two aims were set in this study: to re-analyze the storm surge associated with an artificial Taisho Typhoon, which is constructed from meteorological condition in 1998 year, on past bathymetry of 1917 by using meteorology-ocean-tide model, and to compare the difference of simulated storm surge between on present and past bathymetry to evaluate the effect of land-use change in the Tokyo Bay.

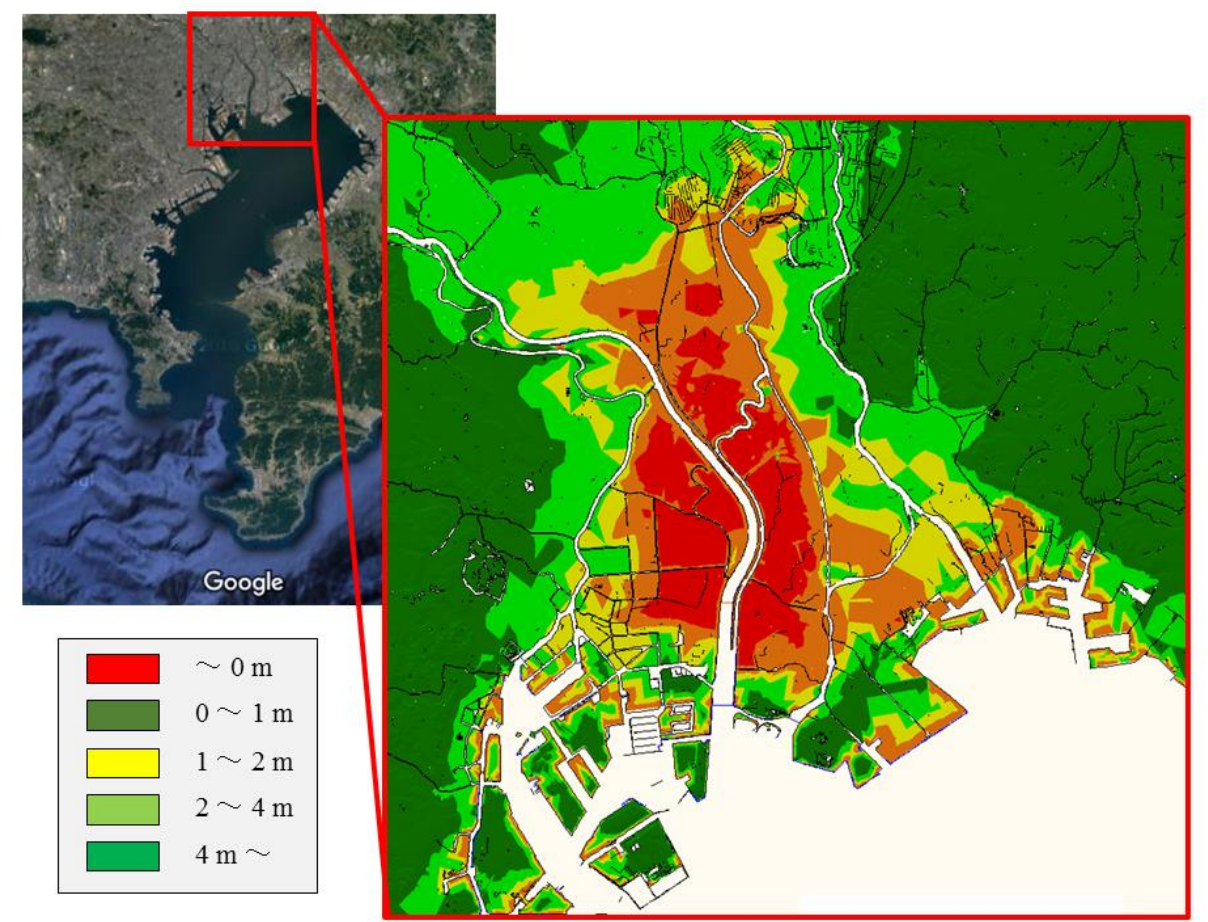

Figure 1. Ground elevation in the Tokyo Bay region (Geospatial Information Authority of Japan, 2016 and Google Map, Image: Landsat, DATA SIO, NOAA, U.S. Navy, NGA, GEBCO, Data Japan Hydrographic Association, Data LDEO-Columbia, NSF, NOAA / Map Data : ZENRIN)

Table 1. Remarkable storm surges in Tokyo Bay (Japan Meteorological Agency, 1994)

\begin{tabular}{|c|c|c|c|c|}
\hline Year & Date & Maximum storm surge (m) & $\begin{array}{c}\text { Minimum central pressure of } \\
\text { typhoon/tropical cyclone (hPa) }\end{array}$ & $\begin{array}{c}\text { Maximum wind } \\
\text { velocity (m/s) }\end{array}$ \\
\hline 1911 & 7.26 & 1.8 & 968.6 & SSE25.9 \\
\hline 1917 & 10.1 & 2.26 & 952.7 & SSE27.7 \\
\hline 1934 & 9.21 & 1.03 & 989.8 & S22.3 \\
\hline 1938 & 9.1 & 1.94 & 978.6 & S31.0 \\
\hline 1949 & 8.31 & 1.41 & 986.1 & SE24.9 \\
\hline 1979 & 10.19 & 1.22 & 976.1 & S17.5 \\
\hline 1985 & 7.1 & 1.63 & 970.0 & S16.7 \\
\hline
\end{tabular}

\section{SHORT DESCRIPTION OF TOKYO BAY}

Tokyo Bay is connected to the Pacific Ocean through the Uraga Channel in a narrow bay mouth. The depth of bathymetry is gradually shallower starting from $50 \mathrm{~m}$ at north of Futtsu Cape in Chiba Prefecture. The slope of sea bottom spreads flat with the ocean depth from 10 to $40 \mathrm{~m}$. On the other hand, the Gulf has a flat bottom and tidelands shallower than 5 meter. There are separations by the slope between the tidelands to the flat bottom at approximately 10 meter in depth. This slope is located at the front of the delta, and the bottom sediments suddenly change from sand to mud with the lower 
edge of the slope. Since the middle of 20th century, port in the Tokyo bay can be considered as the one of the largest port among the world because it includes becoming the coastal industrial area and gigantic urban area. In this process, the bathymetry of the Tokyo Bay was greatly changed. In particular, the most of the shallow water area is no longer in its original shape due to landfill excavation and dredging.

Edo Castle Town and the port were improved after the Edo era, while Tone River and other influx rivers were switched and drilled. The construction of the coastal industrial area by reclamation gradually progressed in Yokohama, Tokyo, Kawasaki and Chiba after Meiji period, but it was not large until around 1930. A part of Keihin industrial area was created by the year 1945 (the final year of the war). However, in the 1960s and 1970s, the landfill in coastal area were progressed on a large scale. Especially, it was remarkable in Keihin industrial area on the north and east coast of Tokyo Bay.

\section{TAISHO TYPHOON}

The life history of 1917 Taisho typhoon is introduced as following. The occurrence of the typhoon was on the eastern part of the Philippine archipelago on 25th Sep. 1917. It gradually proceeded to northwest and reached the eastern part of Luzon Island on $26^{\text {th }}$ Sep. After passing near the Philippines, its direction was changed to the northeast, passing over Daito islands on 29th, landed near Numazu from Suruga Bay on the midnight. In the vicinity of Tokyo Bay, the typhoon speed was at approximately $90 \mathrm{~km} / \mathrm{h}$, passing around Urawa near 03:00 JST $1^{\text {st }}$ Oct. Finally, the typhoon passed the east of Ou Mountains and disappeared in the Sea of Okhotsk on $2^{\text {nd }}$ Oct. (Fig. 2).

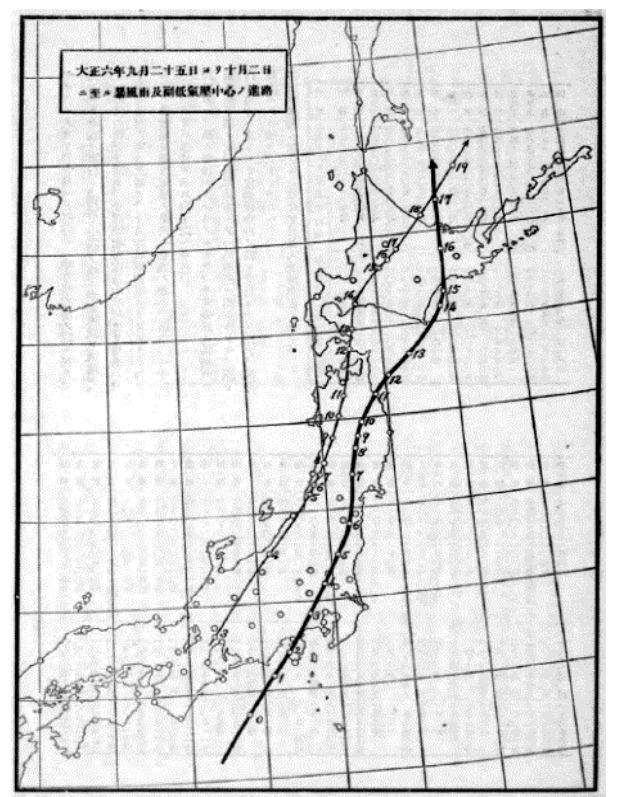

Figure 2. Track of 1917 Taisho typhoon (the Central Meteorological Observatory, 1926a)

The 1917 Taisho typhoon caused a massive flooding from both storm surge and from river flood. The damage in the residential region was following: The death toll reached 1301, the number of injured was 2215 , the number of completely destroyed houses was 43083 , the number of drained houses was 2399, partially destroyed houses was 21010 and flooded above floor level was 194698 (Miyazaki, 2003). It should be noted that major reason of the coastal suffering was a combination of the storm surge and high astronomical tide. Therefore, the damaged areas were extensive from the center of Tokyo metropolitan to west of Chiba prefecture (Miyazaki, 2003). Figure 3 shows the inundated and damaged areas. The storm surge flooded to the vicinity of Ueno and Mukojima and it was approximately $6 \mathrm{~km}$ distance from the coastal line. As a result of the storm surge, the coastal area was covered with seawater as far as residents were able to see it. In addition to the damage in the residential region, salt pan was destroyed by the storm surge, which is a major reason for the end of salt production lasted more than 1000 years. Furthermore, not only salt pan but also paddy fields and seaweed suffered great damage. 


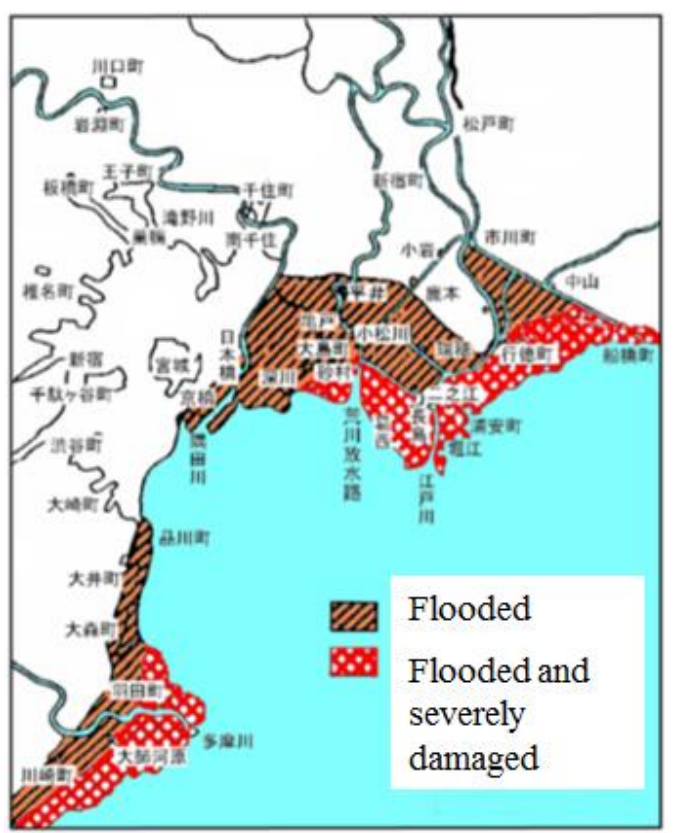

Figure 3. Flooded and damaged area (MLIT, 2013)

\section{NUMERICAL MODEL}

In the present, an evaluation of storm surge has been conducted using weather models based on the atmospheric physical field as external force (e.g. Chen et al., 2012; Nakamura et al., 2016). In this study, for the numerical simulation of storm surge due to typhoon, a coupled meteorology-ocean-tide model was used. Figure 4 shows Model flow of the Coupled meteorology-ocean-tide model and Figure 5 shows Model steps to simulate storm surge.

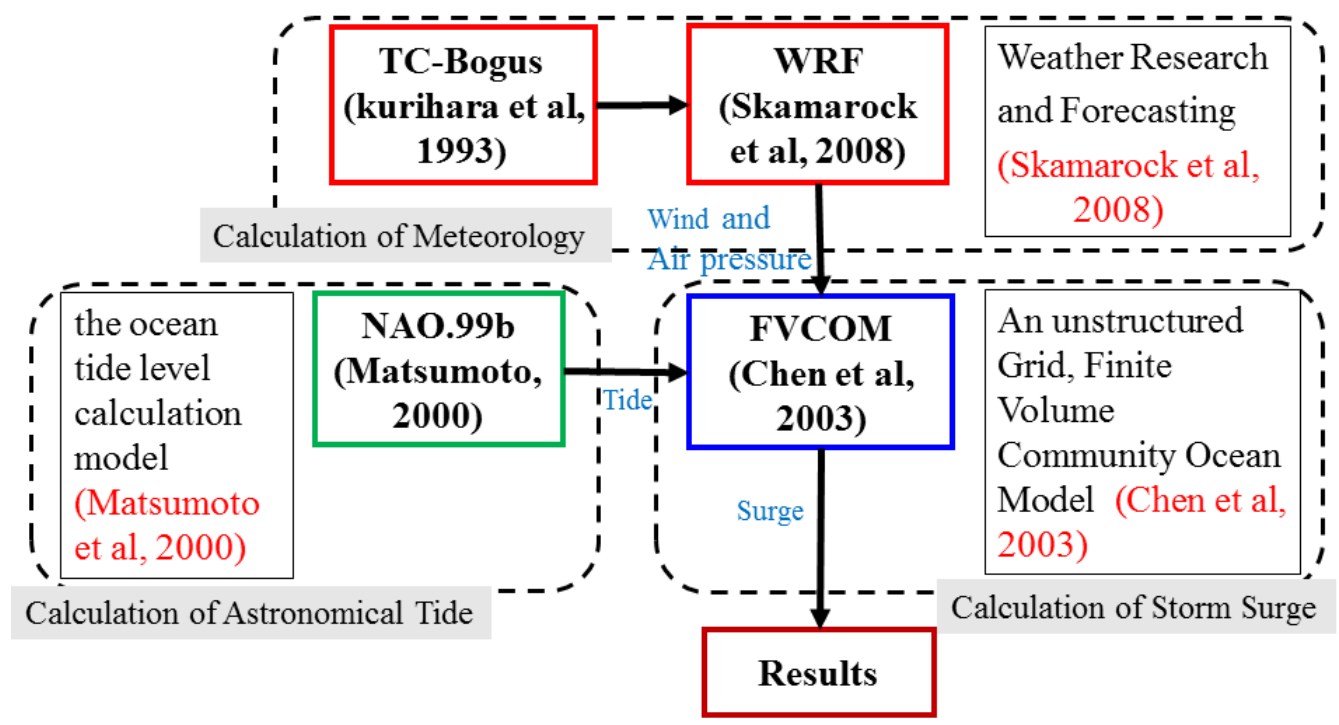

Figure 4. Model flow of the Coupled meteorology-ocean-tide model 

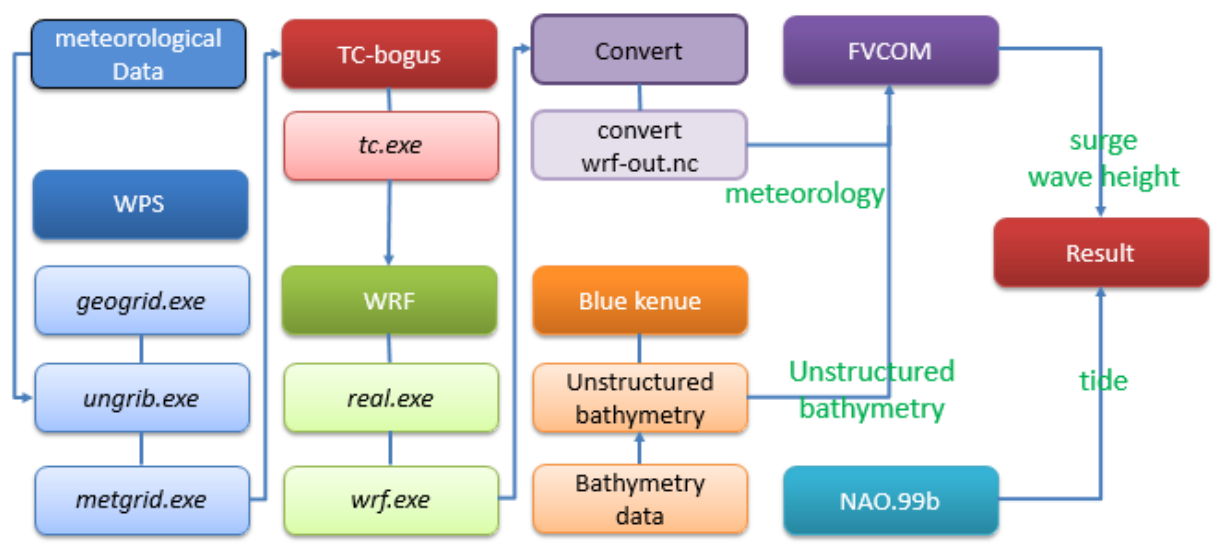

Figure 5. Model steps to simulate storm surge

The NCAR version 3.5.1 of Advanced Research of Weather Research and Forecasting (ARWWRF, Skamarock et al., 2008) model with 2-way nesting was used to investigate the weather field of 1917 Taisho typhoon. The initial and boundary condition in WRF was provided by using NCEP global final analysis (FNL) data using the WPS (WRF Pre-processing System) software package. FNL data is a reanalysis meteorological data of 6-hour time interval, 1.0 arc degree grid interval with 27 vertical layers. TC-Bogus scheme was applied to create bogus 1917 Taisho Typhoon. This scheme can reproduce bogus based typhoon with inserting the structures of artificial typhoon based on Rankine vortex (Kurihara et al, 1993, Hsiao et al., 2010). In order to use bogus based typhoon, it is necessary to set typhoon parameters. Radius of maximum wind was calculated by using Kato's empirical formula (Kato, 2005).

Kato's empirical formula

$$
\begin{array}{ll}
r_{0}=0.77 P_{C}-651 & {\left[P_{C}<950\right]} \\
r_{0}=1.63 P_{C}-1471 & {\left[P_{C}>950\right]}
\end{array}
$$

In which $r_{0}$ : maximum wind velocity radius $(\mathrm{km}) \quad P_{C}:$ minimum pressure $(\mathrm{hPa})$

To reproduce typhoon more accurately with TC-bogus scheme, reanalysis meteorological data is necessary. However, since the 1917 Taisho typhoon was old event, it does not exist. Therefore, we used a similar typhoon's reanalysis data instead of real 1917 Taisho typhoon data. Typhoon No.5 of 1998 was chosen in this study. Figure 6 shows comparison of typhoon track of 1917 and No.5 in 1998. This typhoon was passed almost the same track as 1917 Taisho typhoon. Figure 7 shows comparison of the spatial distribution of atmospheric pressure of Taisho Typhoon and typhoon No.5 in 1998. The distribution of atmospheric pressure was also similar to 1917 Taisho typhoon.

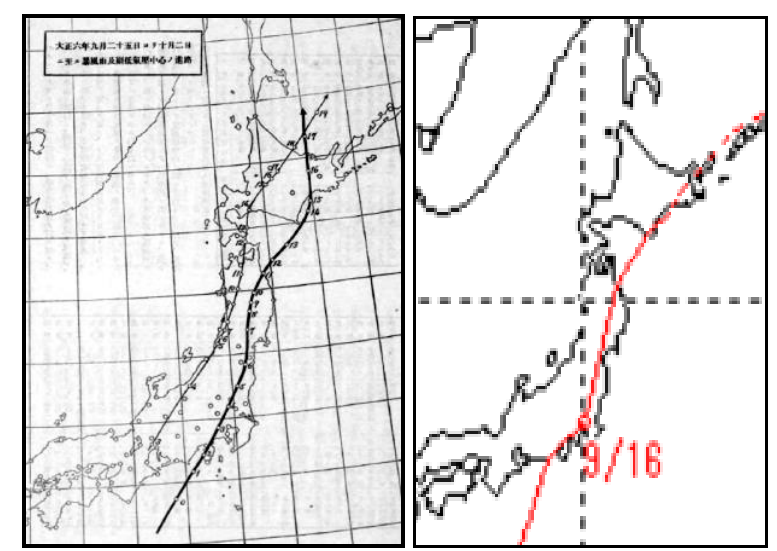

Figure 6. Comparison of typhoon track (left: 1917 Taisho typhoon (the Central Meteorological Observatory, 1926a), right: typhoon No.5 in 1998 (Japan Meteorological Agency, 1998) 

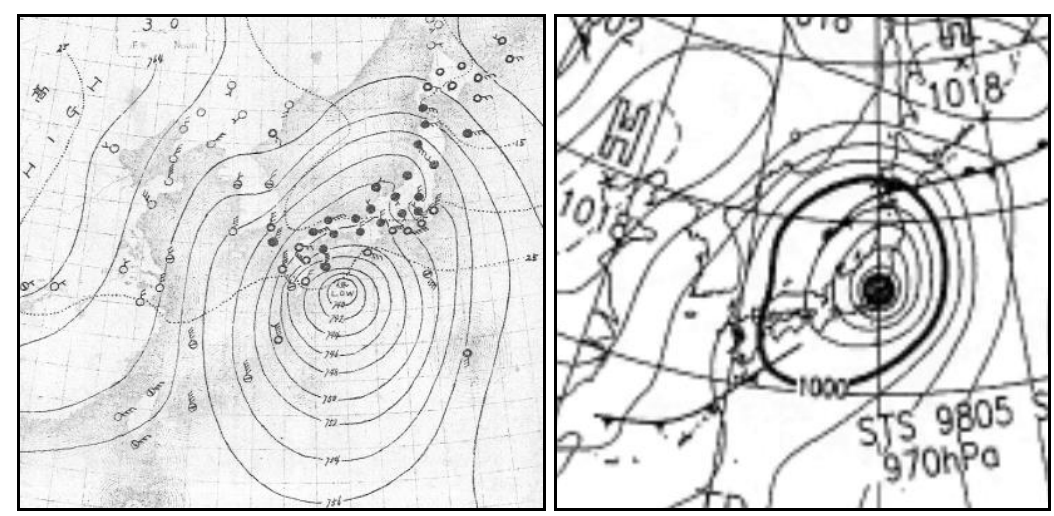

Figure 7. Comparison of the distribution of atmospheric pressure (left: 1917 Taisho typhoon (the Central Meteorological Observatory, 1926a), right: typhoon No.5 in 1998 (Japan Meteorological Agency, 1998))

Results of wind and pressure on sea surface level were extracted to be used as forcing fields for the Finite Volume Community Ocean Model (FVCOM), estimating the water level. FVCOM is a prognostic, unstructured-grid, Finite-Volume, free surface, three dimensional (3-D) primitive equations Community Ocean Model developed by Chen et al. (2003). The open boundary of FVCOM was set as astronomical tide oscillation obtained from NAO.99b (Matsumoto et al., 2000), which is a global ocean tide model. This tidal model was used for the simulation of the tide at each point.

To create past bathymetry, both elevation by using topographic maps of the Land Surveying Department of Japan Imperial Army (surveyed 1917-1922) and ocean water depth by using bathymetric charts introduced by the Hydrographic Department of Japan Imperial Navy (surveyed 1915-1917) were used. For the current topography, the mesh data were used (grid interval: 150 meter) from the Central Disaster Management Council (Cabinet Office, Government of Japan, 2012). The past geographical data of 1917 was created by the following procedure. Firstly, we gather and scan the above topographic maps and charts. Secondly, we input elevation and depth data by our hands on QGIS (QGIS Development Team, 2014). Thirdly, we interpolate values using inverse distance weighting method (IDW). Finally, we generate the mesh data based on the interpolated values (Fig. 8).
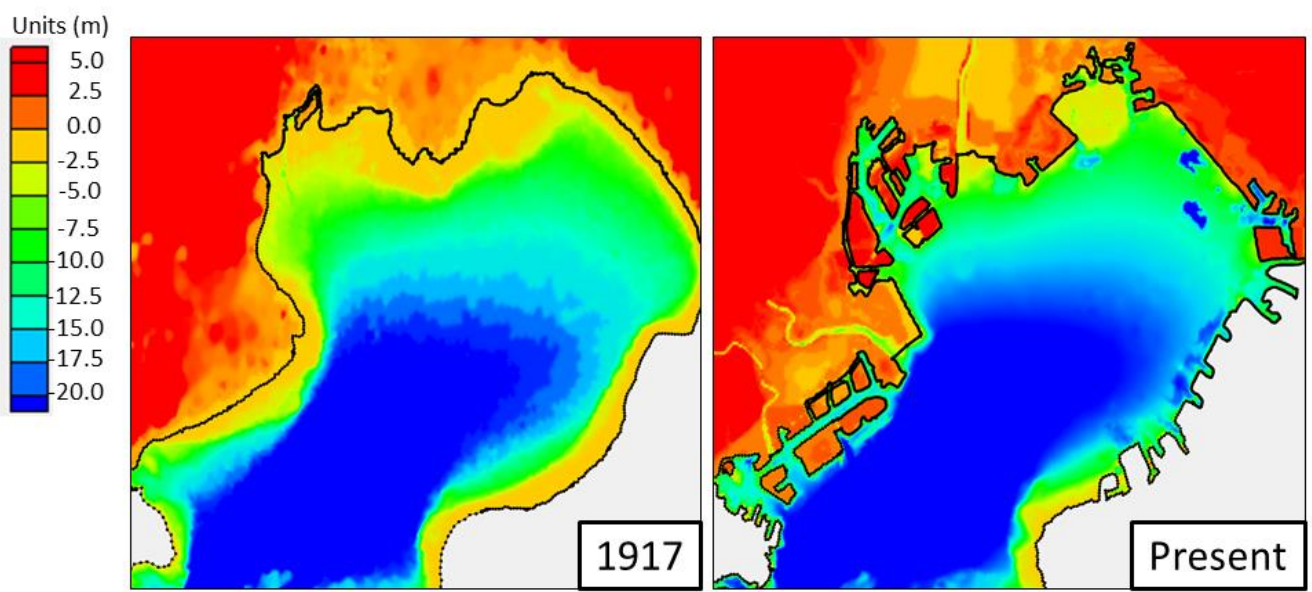

Figure 8. The land and oceanic topography around Tokyo Bay in 1917 (left) and present (right).

\section{CALCULATION CONDITIONS}

The model was run for 36 hours with a time step of $150 \mathrm{~s}$ for the parent domain and $30 \mathrm{~s}, 6 \mathrm{~s}$ and $2 \mathrm{~s}$ for the nested domains respectively. Fig. 9 shows both the parent and nested domains for the WRF simulation. The calculation conditions are summarized in Table. 2. The WRF ARW forecasted $10 \mathrm{~m}$ wind data for the domain 3 was used in the FVCOM model to estimate the surge field. 

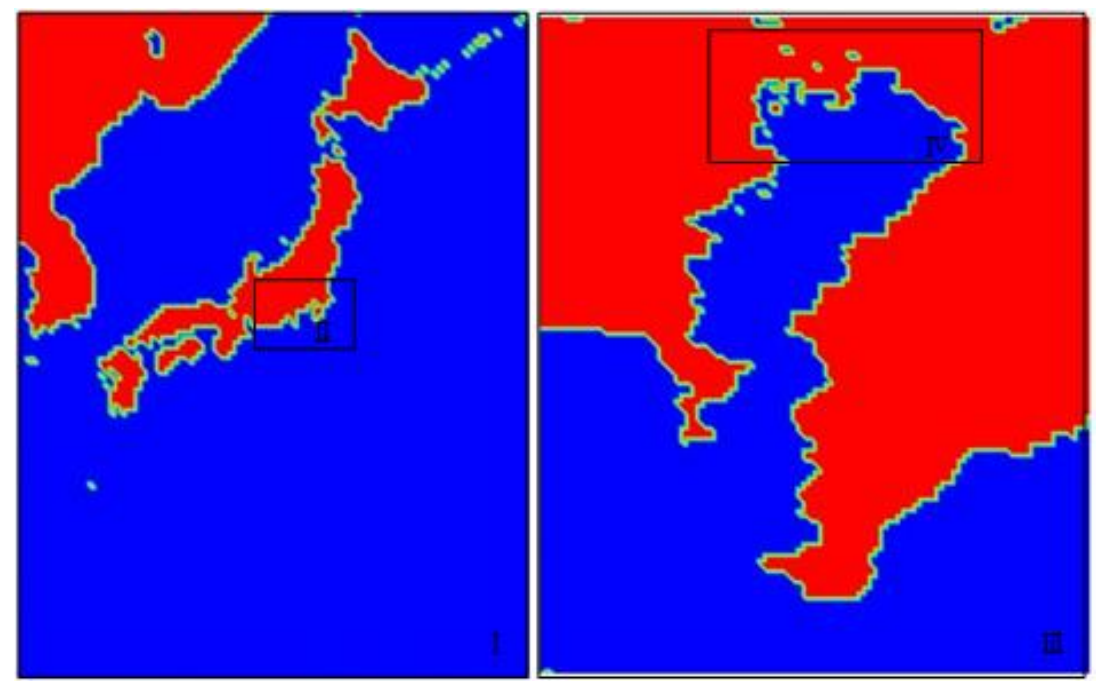

Figure 9. Model domain used for WRF

Table 2. Calculation conditions for storm surge simulation

\begin{tabular}{|c|c|c|}
\hline \multirow{16}{*}{ WRF } & Time(UTC) & 1998/9/15/ 0:00 9/16 12:00 \\
\hline & Domain I & $\begin{array}{l}\mathrm{N} 19^{\circ} 58^{\prime} \sim 46^{\circ} 03^{\prime} \\
\mathrm{E} 125^{\circ} 54^{\prime} \sim 150^{\circ} 06^{\prime}\end{array}$ \\
\hline & \multirow{2}{*}{ Domain II } & $\mathrm{N} 32^{\circ} 41^{\prime} \sim 35^{\circ} 09^{\prime}$ \\
\hline & & $\mathrm{E} 135^{\circ} 12^{\prime} \sim 140^{\circ} 36^{\prime}$ \\
\hline & \multirow{2}{*}{ Domain III } & $\mathrm{N} 34^{\circ} 48^{\prime} \sim 35^{\circ} 46^{\prime}$ \\
\hline & & $\mathrm{E} 139^{\circ} 24^{\prime} \sim 140^{\circ} 18^{\prime}$ \\
\hline & \multirow{2}{*}{ Domain IV } & $\mathrm{N} 35^{\circ} 30^{\prime} \sim 35^{\circ} 44^{\prime}$ \\
\hline & & E139 $42^{\prime} \sim 140^{\circ} 06^{\prime}$ \\
\hline & \multirow{2}{*}{ Horizontal Mesh Number } & I $: 100 \times 130 \quad$ II $: 111 \times 81$ \\
\hline & & III : $101 \times 121 \quad$ IV : $121 \times 91$ \\
\hline & \multirow{2}{*}{ Horizontal Resolution (m) } & I : $22500 \times 22500 \quad$ II $: 4500 \times 4500$ \\
\hline & & III : $900 \times 900 \quad$ IV $: 300 \times 300$ \\
\hline & Projection & Mercator \\
\hline & Vertical Layer & 36 layer \\
\hline & Time Step & I :150s $\quad$ II :30s $\quad$ III :6s $\quad$ IV:2s \\
\hline & Geographical Data & I , II , III:USGS(30s) IV:SRTM3(0.5s) \\
\hline \multirow{9}{*}{ FVCOM } & Time (UTC) & 1998/9/15 0:00 9/16 12:00 \\
\hline & \multirow{2}{*}{ Calculation Area } & \multirow{2}{*}{$\begin{array}{l}\mathrm{N} 35^{\circ} 14^{\prime} \sim 35^{\circ} 42^{\prime} \\
\mathrm{E} 139^{\circ} 37^{\prime} \sim 140^{\circ} 07^{\prime}\end{array}$} \\
\hline & & \\
\hline & Horizontal Mesh Number & Node :23562 \\
\hline & Horizontal Resolution (m) & $150 \times 150$ \\
\hline & Projection & Mercator \\
\hline & Input Data & Calculation Results of WRF (wind velocity and pressure) \\
\hline & & Generated Mesh Data (1917) \\
\hline & Geographical Data & $\begin{array}{c}\text { Central Disaster Management Council: Data for Tsunami } \\
\text { Analysis }(150 \mathrm{~m})\end{array}$ \\
\hline \multirow{4}{*}{ NAO.99b } & Time (UTC) & $1917 / 9 / 2914: 00 \sim 10 / 12: 00$ \\
\hline & Calculation Points & A:Reiganjima B:Komatsugawa C:Horie \\
\hline & & Generated Mesh Data (1917) \\
\hline & Geographical Data & $\begin{array}{c}\text { Central Disaster Management Council: Data for Tsunami } \\
\text { Analysis }(150 \mathrm{~m})\end{array}$ \\
\hline
\end{tabular}




\section{EVALUATION OF THE CALCULATION RESULTS}

The timehistory of estimated sea level pressure (SLP) at the Central Meteorological Observatory was in good agreement with observations (Fig. 11). Also, the value of wind velocity was similar to observations, except for during measuring the peak values (Fig. 12). This was because the values of the wind velocity from WRF were averaged in the size of grid, thus making it difficult to examine the accurate values. The track of typhoon was roughly consistent with the track of observation with the maximum error of $20 \mathrm{~km}$, especially where the typhoon was approaching near the Tokyo Bay (Fig. 10).

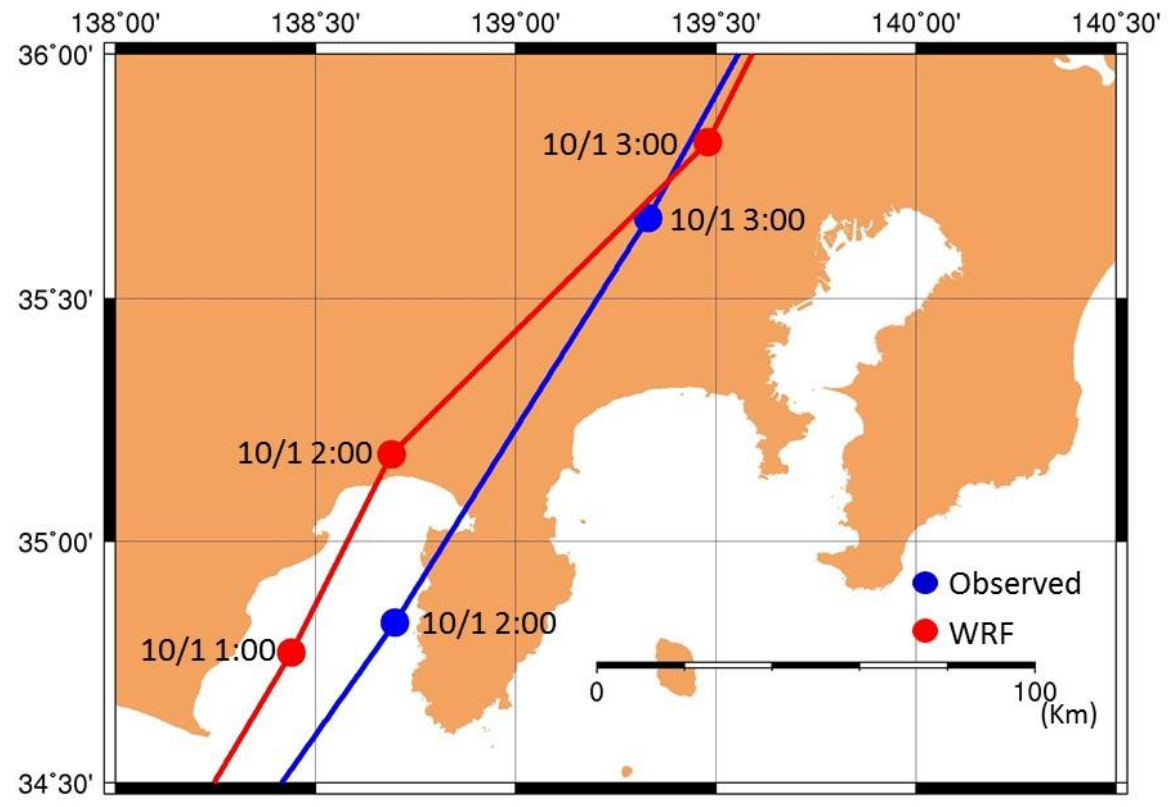

Figure 10. Results of calculated typhoon track compared with the observation presented by The Central Meteorological Observatory.

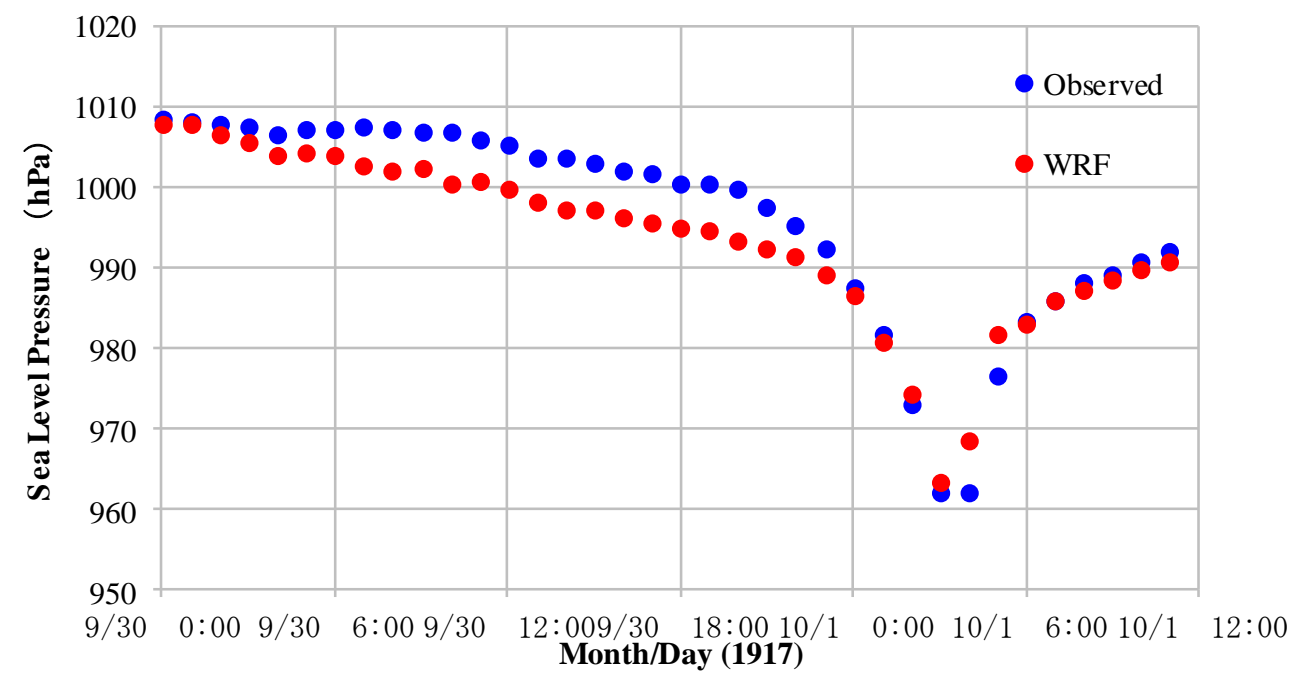

Figure 11. Results of sea level pressure at The Central Meteorological Observatory. 


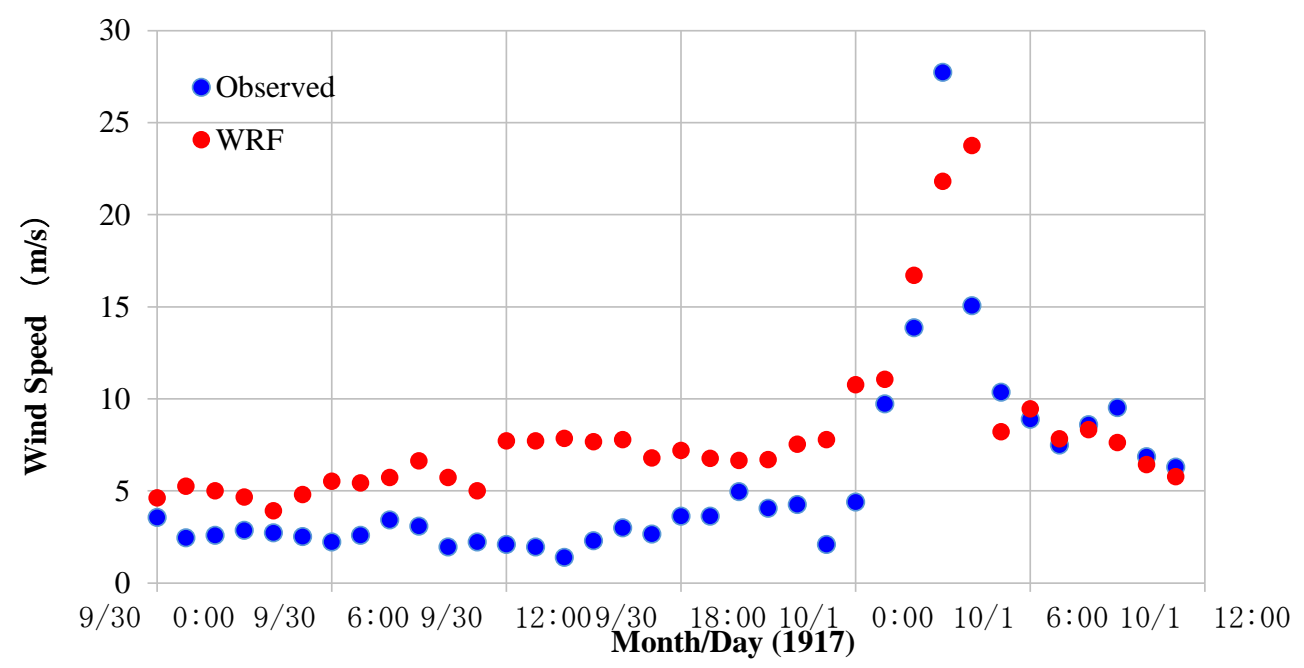

Figure 12. Results of wind speed of the simulation and observation at the Central Meteorological Observatory.

\section{RESULTS and DISCUSSION}

The storm surge (both wind and pressure driven surge) simulated by FVCOM model lies within the range of 0.2 to $0.6 \mathrm{~m}$ for the observed points. Figure 14 shows the calculation results for inundation area and depth, with matching survey results map. When comparing the calculation results to observed values, three points were selected: Reiganjima, Komatsugawa, and Horie. These three points are the locations of tide stations. For the area spanning from Mukoujima to Ichikawa, there was inundation reaching even areas away from the shoreline (approximately $6-10 \mathrm{~km}$ ) due to the spreading shallow water area. By contrast, the area spanning from Funabashi and to eastward was a plateau behind the coastline, so the scale of inundation was limited to those areas along the coast. The reproduced past surge levels matched with the records with the tide station and the height of the measured water mark at Reiganjima. Although the value of second peak of the water level could not be reproduced probably because of lack of river information in Komatsugawa, the increment before reaching the peak and the value of first peak was quite similar to the observation (Fig. 13). In addition, the storm surge simulation based on present bathymetry was performed. The water levels were approximately $0.8 \mathrm{~m}$ lower than those based on the past bathymetry. This difference was mainly because the present bathymetry is much deeper than that of nearly 100 years ago. Figure 15 shows Comparison of maximum storm surge height in the respective positions.

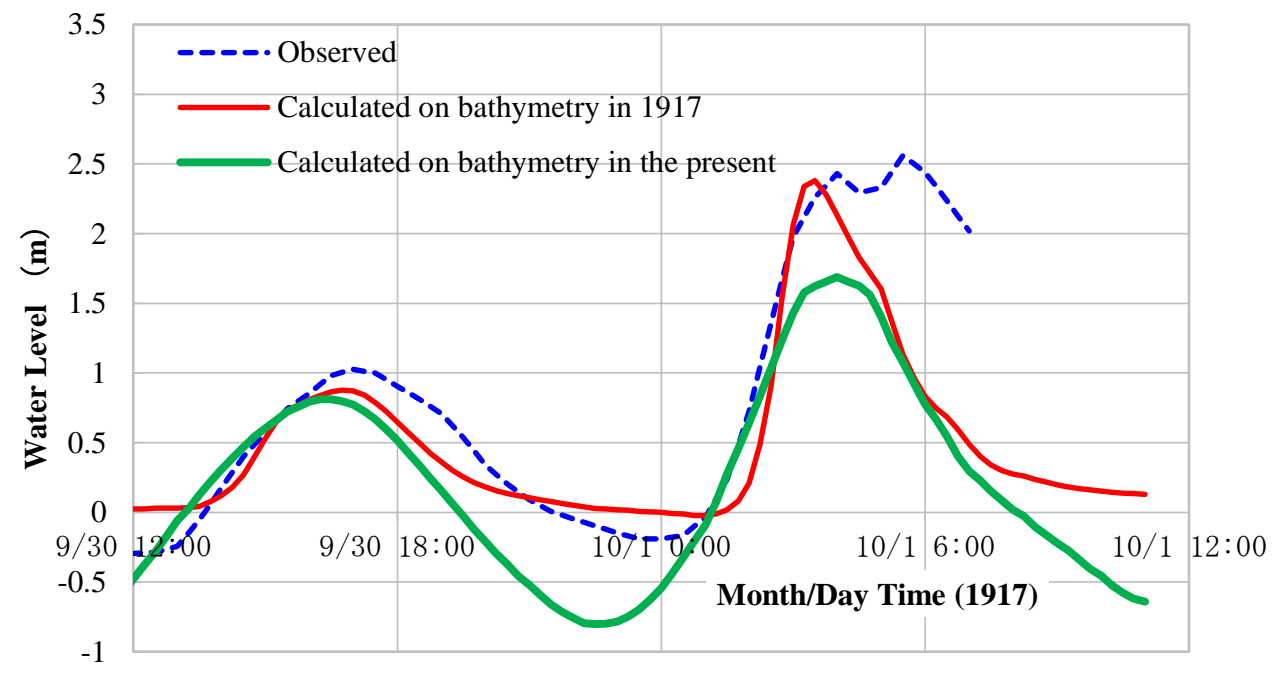

Figure 13. Comparison of water level height at Komatsugawa. 


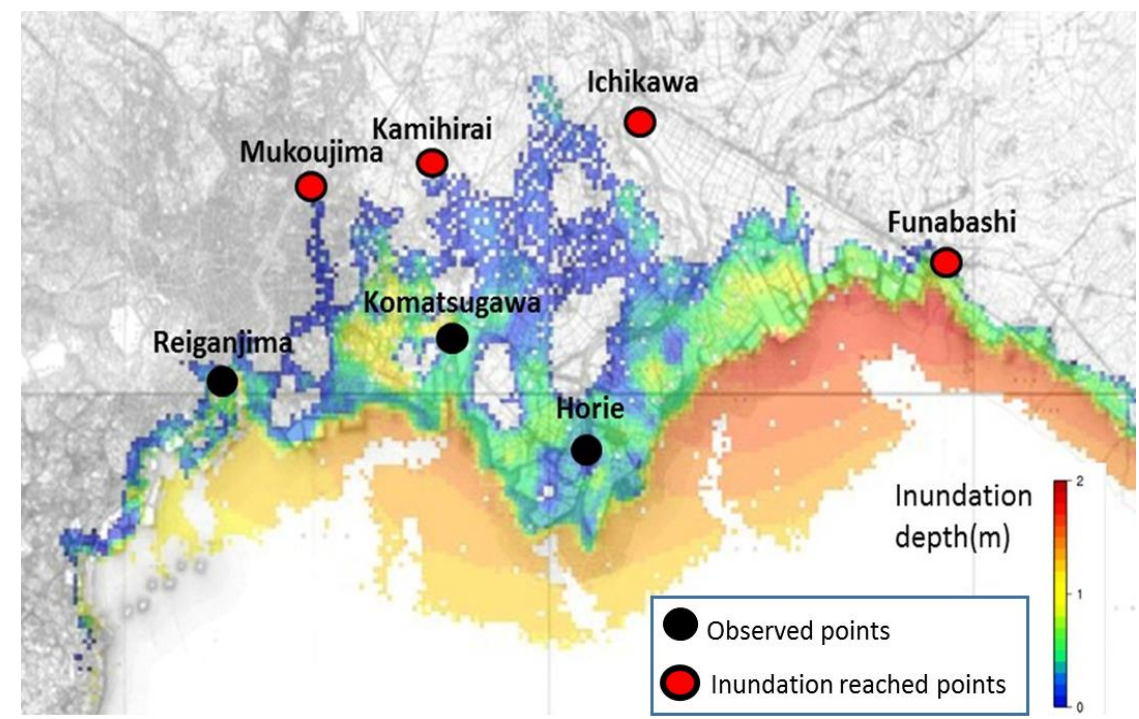

Figure 14. Inundation area on past bathymetry of 1917

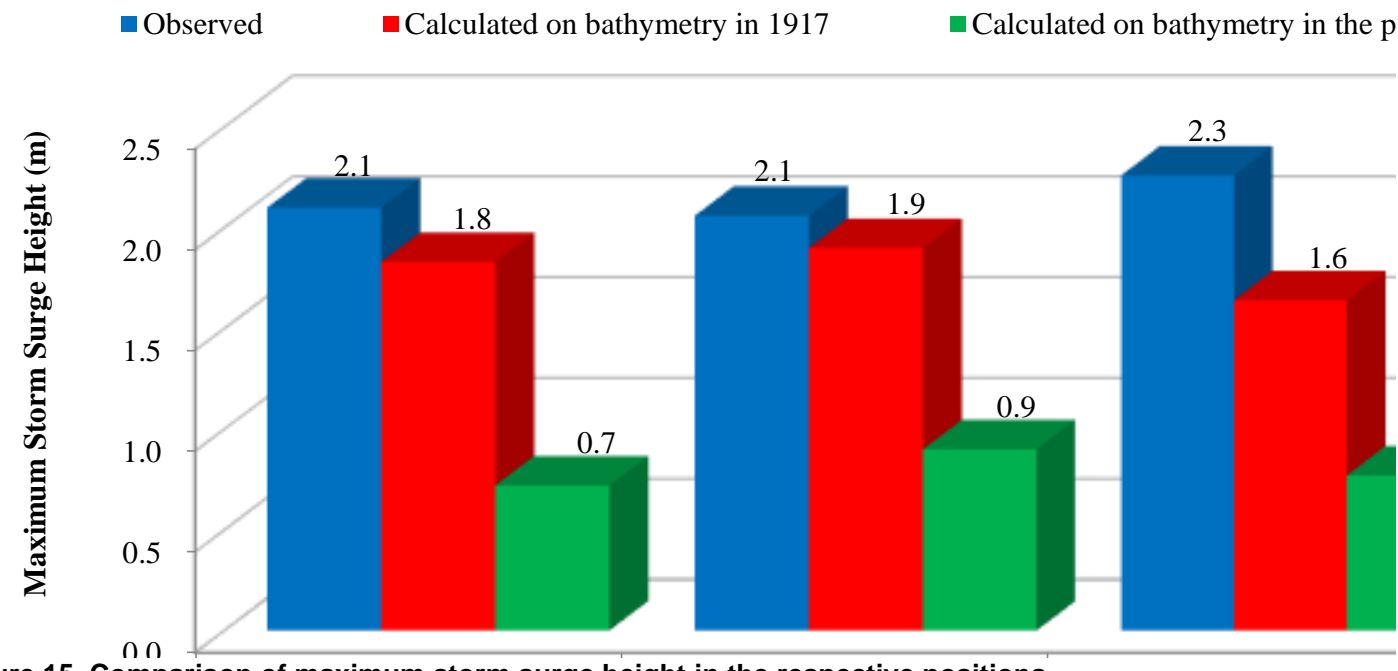

Figure 15. Comparison of maximum storm surge height in the respective positions

\section{CONCLUSION}

In this study, the storm surge associated with 1917 Taisho Typhoon was faithfully reproduced. From the results, it can be said that the behavior of the storm surge is greatly different between on past and present bathymetry.

This study possesses two major important findings. The first is that past storm surge occurred mainly because of shallow water area spanning over inner bay. The second is that the high vulnerable area affected by storm surge has been shifted from mudflat shallow area in the inner bay to the belowsea-level inland area, due to landfill and urbanization which have continued approximately 100 years after the storm. It can be indicated that the bathymetry shifting due to human activity has a great influence to changing the effects of coastal disasters even in the same location.

If we assess the future possible coastal risks for long terms, the expected long-term land-use changing should be considered. It can be said that long-term land-use changes are clearly important and they give great impacts to the risk of future possible coastal hazard. 


\section{ACKNOWLEDGMENTS}

The present work was supported by the program for the Strategic Research Foundation at Private Universities from Ministry of Education (No. S1311028, Tomoya Shibayama) and Grant-in-Aid for JSPS Fellows (No.16J07998, Ryota Nakamura).

\section{REFERENCES}

Cabinet Office, Government of Japan, 2012. Committee for Giant Earthquake Model Study of the Nankai Trough, http://www.bousai.go.jp/jishin/nankai/model/data_teikyou.html, accessed 17 June 2014. (in Japanese)

Chen, C., H., Liu, R. C. Beardsley. 2003. An Unstructured, finite-volume, three-dimensional, primitive equation ocean model: application to coastal ocean and estuaries. Journal of Atmosphere and Oceannic Technology., 20, 159-186.

Chen, C., Limeburner, R., the members of the UMASS-D FVCOM Group, Gao, G., Xu, Q., Qi, J., Xue, P., Lai, Z., Lin, H. members of the WHOI Field Measurement Group, Beardsley R., Owens B. and Carlson, B. 2012. FVCOM model estimate of the location of Air France 447, Ocean Dynamics, 62.6, 943-952.

Civil Engineering Support and Training Center, Bureau of Construction and Tokyo Metropolitan Government. 2013. The survey report for ground subsidence of 2013. http://www.kensetsu.metro.tokyo.jp/content/000009786.pdf, accessed 27 Feb 2017. (in Japanese)

Esteban, M., Mikami, T., Shibayama, T., Takagi, H., Jonkman, S.N. and Ledden, M.V. 2014. Climate change adaptation in Tokyo Bay: The case for a storm surge barrier, Proceedings of the 34th International Conference on Coastal Engineering (ICCE), Seoul, Korea.

Geospatial Information Authority of Japan. 2016. Foundation map information, http://www.gsi.go.jp/kiban/index.html, accessed 10 Sep 2016. (in Japanese)

Hoshino, S., M. Esteban, T. Mikami, H. Takagi, and T. Shibayama. 2016. Estimation of increase in storm surge damage due to climate change and sea level rise in the Greater Tokyo area, Natural Hazards, 80(1), 539-565.

Hsiao, L.F., Liou, C.S., Yeh, T.C., Guo, Y.R., Chen, D.S., Huang, K.N., Terng, C.T. and Chen, J.H. 2010. A vortex relocation scheme for tropical cyclone initialization in advanced research WRF, Monthly Weather Review, 138, 3298-3315.

Japan Meteorological Agency. 1994. Meteorology and Ocean Handbook, No.13, part of Tokyo Bay. (in Japanese)

Japan Meteorological Agency. 1998. 5th Typhoon in 1998, http://www.data.jma.go.jp/obd/stats/data/bosai/report/1998/19980915 /19980915.html, accessed 10 June 2014. (in Japanese)

Kato, F. 2005. Study of storm surge risk assessment, National Institute for Land and Infrastructure Management reports, 275, p10.

Kurihara, Y., Bender, M.A. and Ross, R.J. 1993. An Initialization Scheme of Hurricane Models by Vortex Specification, Monthly Weather Review, 121, 2030-2045.

Matsumoto, K., Takanezawa, T. and Ooe, M. 2000. Ocean Tide Models Developed by Assimilating TOPEX/POSEIDON Altimeter Data into Hydrodynamical Model: A Global Model and a Regional Model around Japan, Journal of Oceanography, 56, 567-581.

MLIT, 2013. To protect people from massive flooding caused storm surge associated with supertyphoon (edited by integrated survey group of both MLIT and conference for disaster prevention, and ADD): The figure of past water disaster "Kanto water disaster" -storm surge- (this figure is originally from JMA technical report), http://www.mlit.go.jp/river/bousai/bousai-gensai/bousaigensai/pdf/1kairef03-02-01.pdf, assessed 27 Sep 2017. (in Japanese)

Miyazaki, M. 2003. Study of storm surge, Seizando-shoten, 134p, 30-33.

Nakamura, R., Shibayama, T., Esteban, M. and Iwamoto, T. 2016. Future Typhoon and Storm Surges under Different Global Warming Scenarios: Case Study of Typhoon Haiyan (2013), Natural Hazards, 82(3), 1645-1681.

National Centers for Environmental Prediction, National Weather Service, NOAA and U.S. Department of Commerce. 1997. NCEP FNL Operational Model Global Tropospheric Analyses, April 1997 through June 2007. Research Data Archive at the National Center for Atmospheric Research, Computational and Information Systems Laboratory. Dataset, https://doi.org/10.5065/D6FB50XD. accessed 1 October 2014. 
Ohira, K., Shibayama, T. and Esteban, M. 2012. Forecasting Change of Wave and Storm Surge Damage caused by Typhoon Affected by Climate Change -Development of Meteorology-WaveStorm Surge-Tide Coupled Model and Long Term Prediction-, Journal of Japan Society of Civil Engineers, Ser. B2 (Coastal Engineering), 68(2), I_291-I_295.

QGIS Development Team, 2014. QGIS Geographic Information System. Open Source Geospatial Foundation Project. http://www.qgis.org/, accessed 20 June 2014.

Skamarock, W.C., Klemp, J.B., Dudhia, J., Gill, D.O., Barker, D.M., Duda, M.G., Huang, X.Y., Wang, W. and Power. J.G. 2008. A Description of the Advanced Research WRF Version 3. NCAR TECHNICAL NOTE.

The Central Meteorological Observatory. 1918. The Central Meteorological Observatory Monthly Report, Taisho 6th year (September - December), 73-75. (in Japanese)

The Central Meteorological Observatory. 1926a. the Central Meteorological Observatory Annual Report, Taisho 6th year, weather chart part. (in Japanese)

The Central Meteorological Observatory. 1926b. the Central Meteorological Observatory Annual Report, Taisho 6th year, rainstorm part. (in Japanese)

The Central Meteorological Observatory. 1931. Weather Miscellaneous Collection, Vol. 1, p191. (in Japanese)

Tokyo Metropolitan Government, Kanagawa Prefectural Government and Chiba Prefectural Government. 2004. Tokyo Bay Basic Plan on Coastal Management. (in Japanese)

Wadachi, K. and Matsuo, K. 1939. The study of tsunami in Tokyo Bay caused by typhoon, Sea and Sky, Vol.19, No.3, 8-14. (in Japanese) 